\title{
Missed medical appointment among hypertensive and diabetic outpatients in a tertiary healthcare facility in Ibadan, Nigeria
}

\author{
Aje A Akinniyi ${ }^{\star}$ and Olajide O Olamide \\ Department of Clinical Pharmacy \& Pharmacy Administration, Faculty of Pharmacy, University of Ibadan, Ibadan, Nigeria
}

*For correspondence: Email: aje123@gmail.com: Tel: +2348035684484

Sent for review: 15 March 2017

Revised accepted: 27 May 2017

\begin{abstract}
Purpose: To explore the reasons for missed medical appointment, patients' awareness on its consequences; and to find strategies to reduce it among the study population.

Methods: This was a descriptive cross-sectional survey among 300 hypertensive and 200 diabetic outpatients assessing care at the University College Hospital, Ibadan. Descriptive statistics was used to summarize data and categorical variables were compared with Chi-square at a level of significance set at $p \leq 0.05$.

Results: For hypertensive respondents, $16.7 \%$ missed $>30 \%$ of scheduled medical appointments while for diabetic respondents, it was $13.0 \%$; $59.7 \%$ of the hypertensive respondents and $63.5 \%$ of the diabetic respondents adhered to their medications. The reasons for missed medical appointments include forgetfulness, lack of funds for transport, conflicting commitments, etc. The level of awareness on the possible impact of missed medical appointments is low. Most of the respondents were of the opinion that those who missed appointments should be penalized, although a majority of them disagreed with the option of introducing financial penalties.

Conclusion: The findings indicate that the reasons for missed medical appointment is mainly due to delay in attending to un-booked patients until all the scheduled patients are seen in order to reduce appointment non-adherence.
\end{abstract}

Keywords: Missed medical appointments, Hypertensive, Diabetic outpatients, Medication adherence, Patient awareness

Tropical Journal of Pharmaceutical Research is indexed by Science Citation Index (SciSearch), Scopus, International Pharmaceutical Abstract, Chemical Abstracts, Embase, Index Copernicus, EBSCO, African Index Medicus, JournalSeek, Journal Citation Reports/Science Edition, Directory of Open Access Journals (DOAJ), African Journal Online, Bioline International, Open-J-Gate and Pharmacy Abstracts

\section{INTRODUCTION}

Chronic diseases such as hypertension and diabetes require lifelong commitment to medication and scheduled appointments for routine medical review [1,2]. Proper management of these conditions are important to prevent severe complications which could cause increased morbidity and mortality [2]. Routine follow up appointments for medical review are an important aspect of medical care. It provides an important avenue for patient education, medication titration and early detection of complications [3]. Unfortunately patients do not benefit maximally from disease management programs because the quality of care is currently been flawed by high levels of missed medical appointments also known as 'No show' [4,5].

The problem of missed medical appointment has long been considered an outpatient clinic operation problem that disrupts providers' care plan [6]. It is a major barrier to the effective delivery of healthcare, because when patients 
miss scheduled medical appointments, continuity of care is interrupted, appropriate monitoring of health status lapses and the cost of health services increases [4]. Missed appointments constitute a challenge for clinicians and clinical administrators because it is a source of inefficiency and waste of resources in health facilities [7]. Missed medical appointment is common among hypertensive and diabetic outpatients $[4,5]$. The literature has established that the rates of missed medical appointments are unacceptably high [8]. The prevalence of missed medical appointments varies between countries, healthcare system and clinic settings but on an average $5-55 \%$ of scheduled medical appointments are missed [8-10].

Several reasons have been cited to explain why patients miss their medical appointments. Forgetting appointment has been the most popular and commonly cited reason [11]. Logistical issues reported include transportation difficulties, long distance travel to the clinic, trouble getting off work, child care [11].

This study therefore seeks to explore the reasons for missed medical appointment, patients' awareness on its consequences; and to find possible strategies to reduce it among the study population.

\section{METHODS}

\section{Study site}

This study was carried out in the medical outpatient clinic of the University College Hospital (UCH), Ibadan, Oyo State, SouthWestern Nigeria for a period of 12 weeks between July to September, 2016. UCH is a 900bed tertiary health facility located in Ibadan and affiliated with the University of Ibadan. This healthcare facility caters for the healthcare needs of several categories of ambulatory and institutionalized patients within and outside the region.

\section{Study design}

The study employed a descriptive cross-sectional method to explore relevant aspects of missed medical appointment among hypertensive and diabetic outpatients using pretested questionnaires. Ethical approval was obtained from the joint University of Ibadan and University College Hospital Ethics Committee; reference no EC/05/01/2008a. The study was carried out by following the principles outlined in Helsinki declaration of 1964 [12].

\section{Sample size}

The sample size was determined based on the data available from the medical record unit of the study site. The records showed that an average of 50 hypertensive and 30 diabetic patients attended the cardiology and endocrinology outpatient clinics of the hospital respectively each week. Based on the estimated population of 600 hypertensive and 300 diabetic outpatients expected at the clinic within the study period of 12 weeks, at $95 \%$ confidence level and $5 \%$ error margin, 300 hypertensive and 200 diabetic outpatients were included in the study. The sample size was determined using Yamane sample size formula [13].

\section{Sampling technique}

Purposive sampling of all hypertensive and diabetic outpatients who were available at the medical outpatient clinic within the study period and who met the inclusion criteria for the study.

\section{Data collection instrument}

A validated 22-item structured questionnaire comprising both open-ended and closed-ended questions was designed and used to obtain relevant information from the study participants. The questionnaire was divided into sections A-F: Section A contained information on the sociodemographic data as well as the average monthly income and health insurance status of respondents. Section B gathered information on the patients' disease condition, duration of treatment, awareness of the need for routine follow-up clinics and the number of healthcare facilities visited for follow-up, required. Information on respondents' perception on the necessity of routine medical appointments to proper disease management; frequency of routine medical appointments; how routine appointments were communicated and documented; and the frequency of missed medical appointment were also explored in this section. Section C assessed respondents' medication adherence status using the validated 4-item Morisky Medication Adherence Predictor Scale administered in dichotomous pattern (Yes/ No) [14]. Section D contained questions to assess patients' awareness on the possible consequences of missed medical appointments on their own health and healthcare services. Section E sought to identify reasons for missed medical appointments among the study participants. Section F identified respondents' opinion on possible strategies that can be explored to discourage and reduce the rates of missed medical appointments among outpatients. 


\section{Measures and definitions}

Appointment non-adherence: Appointment non-adherence was defined as missing more than 3 out of 10 medical appointments. This was defined by evaluating the distribution of responses to the question "Out of every 10 appointments, on an average how many did you miss?" Missed appointment rates were then grouped into 3 categories: 0 \%, 1-30 \% and > 30 $\%$ using cutoffs from previous adherence studies $[3,4,15]$.

Medication adherence status: Adherence in this study was defined as no positive response (or a total score of zero) to the 4-item questions on the 4-item Morisky Medication Adherence Predictor Scale.

\section{Data analysis}

Data was analyzed using SPSS Version 17 for Windows. Descriptive statistics like frequency counts, percentages, means and standard deviation was used to summarize data and categorical variables were compared with Chisquare at a level of significance set at $p \leq 0.05$.

\section{RESULTS}

Out of 545 patients who gave consent to participate in the study, a total of $500(91.7 \%)$ participants comprising 300 hypertensive and 200 diabetic outpatients properly responded to the validated and pretested data collection tool and these were subsequently considered for analysis. One hundred and seventy-six (58.7\%) of the hypertensive respondents were females, $105(35.5 \%)$ were within $61-70$ years of age, 230 (76.7\%) married and 108 (36.0\%) had no formal education. The mean age of the hypertensive respondents was $62.78 \pm 11.9$ years. Seventyeight $(39.0 \%)$ of the 200 diabetic respondents had co-morbid hypertension. One hundred and twenty-nine $(62.0 \%)$ of the diabetic respondents were females, $67(34.5 \%)$ were in the sixth decade of life, $102(81.0 \%)$ were married and 88 $(44.0 \%)$ were traders. The mean age of the diabetic respondents was $64.2 \pm 12.6$ years. Further details are shown in Table 1.

Table 1: Socio-demographic characteristics of respondents

\begin{tabular}{|c|c|c|c|c|}
\hline \multirow[b]{2}{*}{ Variables } & \multicolumn{2}{|c|}{ Hypertensive $(n=300)$} & \multicolumn{2}{|c|}{ Diabetic $(n=200)$} \\
\hline & Frequency & Percentage (\%) & Frequency & Percentage (\%) \\
\hline \multicolumn{5}{|l|}{ Sex } \\
\hline Male & 124 & 41.3 & 76 & 38.0 \\
\hline Female & 176 & 58.7 & 124 & 62.0 \\
\hline \multicolumn{5}{|l|}{ Age (years) } \\
\hline $30-40$ & 12 & 4.0 & 24 & 12.0 \\
\hline $41-50$ & 32 & 10.7 & 22 & 11.0 \\
\hline $51-60$ & 83 & 27.7 & 34 & 17.0 \\
\hline $61-70$ & 105 & 35.5 & 69 & 34.5 \\
\hline Above 70 & 68 & 22.7 & 51 & 25.5 \\
\hline \multicolumn{5}{|l|}{ Marital status } \\
\hline Single & 7 & 2.3 & 11 & 5.5 \\
\hline Married & 230 & 76.7 & 162 & 81.0 \\
\hline Divorced & 6 & 2.0 & 2 & 1.0 \\
\hline Widowed & 49 & 16.3 & 24 & 12.0 \\
\hline Separated & 8 & 2.7 & 1 & 0.5 \\
\hline \multicolumn{5}{|l|}{ Occupation } \\
\hline Civil servants & 58 & 19.3 & 46 & 23.0 \\
\hline Trader & 121 & 40.3 & 88 & 44.0 \\
\hline Artisans & 43 & 14.3 & 18 & 9.0 \\
\hline Farmers & 25 & 8.3 & 6 & 3.0 \\
\hline Retired & 53 & 17.7 & 42 & 21.0 \\
\hline \multicolumn{5}{|l|}{ Level of education } \\
\hline No formal education & 104 & 34.7 & 77 & 38.5 \\
\hline Primary & 108 & 36.0 & 42 & 21.0 \\
\hline Secondary & 52 & 17.3 & 43 & 21.5 \\
\hline Tertiary & 36 & 12.0 & 38 & 19.0 \\
\hline \multicolumn{5}{|l|}{ Income } \\
\hline No stable income & 78 & 26.0 & 13 & 6.5 \\
\hline$\leq \$ 10,000$ & 89 & 29.7 & 33 & 16.5 \\
\hline$>\$ 10,000-\leq \$ 50,000$ & 66 & 22.0 & 68 & 34.0 \\
\hline$>\$ 50,000-\leq \$ 100,000$ & 22 & 7.3 & 66 & 33 \\
\hline$>\$ 100,000$ & 45 & 15.0 & 20 & 10.0 \\
\hline
\end{tabular}


Only $52(17.3 \%)$ of the hypertensive respondents and 32 (16.0\%) of the diabetic respondents had health insurance coverage for their healthcare needs (Table 1). Information on respondents' duration of treatment, routine medical appointments and missed medical appointments is presented in Table 2 .

Based on responses to the 4-item Morisky Medication Adherence Predictor Scale, 179 (59.7 $\%$ ) of the hypertensive participants were adherent to prescribed medications. Also, 127 $(63.5 \%)$ of the diabetic respondents were adherent to prescribed medication. Data on respondents' reasons for missed medical appointment is presented in Table 3. Data on the level of respondents' awareness of the potential consequences of missed medical appointments on clinical outcomes and healthcare system is presented in Table 4.

One hundred and ninety-three (64.3\%) hypertensive respondents were of the opinion that patient should be punished for habitually/unnecessarily missing follow-up appointments, 100 (33.3 \%) disagreed while 7 $(2.3 \%)$ were indifferent. On the other hand 122 $(61.0 \%)$ diabetic respondents were of the opinion that patient should be punished for habitually/unnecessarily missing follow-up appointments, 72 (36.0\%) disagree while 6 (3.0 $\%)$ were indifferent. The respondents' opinion on disincentives to discourage missed medical appointments are as follows: 62 (20.7 \%) hypertensive and $78 \quad(39.0 \%)$ diabetic respondents would have them fined or overcharged; 5 (1.7\%) hypertensive and 15 (7.5 $\%)$ diabetic respondents would have them turned back; 7 (2.3\%) hypertensive and 23 (11.5\%) diabetic respondents; 189 (63.0\%) hypertensive and $145(72.5 \%)$ diabetic respondents would have them only attended to after all patients booked for the clinic have been seen.

Significant association was found between age range and appointment adherence. There was also association between gender and appointment adherence. For the hypertensive patients, the male patients were more appointment adherent than the female patients; however, with the diabetic patients, the female patients the reverse was the case. The association found between treatment duration and appointment adherence followed a trend showing poor adherence within the first year of treatment and also after five years of treatment. The respondents were more appointment adherent between one and five years of treatment. However, no association was found between medication adherence and appointment adherence. Detailed information on statistically significant relationships for the Chi-square test done between appointment adherence and some variables are presented in Table 5.

Table 2: Responses to relevant information on routine medical appointments

\begin{tabular}{|c|c|c|c|c|}
\hline \multirow[t]{2}{*}{ Variables } & \multicolumn{2}{|c|}{ Hypertension $(n=300)$} & \multicolumn{2}{|c|}{ Diabetic $(n=200)$} \\
\hline & Frequency & Percentage (\%) & Frequency & Percentage (\%) \\
\hline \multicolumn{5}{|l|}{ Duration on treatment } \\
\hline$<1$ year & 46 & 15.3 & 35 & 17.5 \\
\hline 1- 5 years & 173 & 57.7 & 94 & 47.0 \\
\hline$>5$ years & 81 & 27.0 & 71 & 35.5 \\
\hline \multicolumn{5}{|c|}{ Aware of the need for regular follow up visits } \\
\hline Yes & 298 & 99.3 & 199 & 99.5 \\
\hline No & 2 & 0.67 & 1 & 0.5 \\
\hline \multicolumn{5}{|c|}{ Number of hospitals visited for regular follow-up on this condition } \\
\hline 1 & 258 & 86.0 & 167 & 83.5 \\
\hline$>1$ & 42 & 14.0 & 33 & 16.5 \\
\hline \multicolumn{5}{|c|}{ How often are you required to come for routine follow-up in the clinic? } \\
\hline Twice in a month & 8 & 2.7 & 7 & 3.5 \\
\hline Once in a month & 34 & 11.3 & 45 & 22.5 \\
\hline Once in two months & 200 & 66.7 & 120 & 60.0 \\
\hline$\geq$ Once in three months & 58 & 19.3 & 28 & 14.0 \\
\hline \multicolumn{5}{|c|}{ How information on medical appointment is communicated to the patient } \\
\hline Verbally only & 18 & 6.0 & 24 & 12.0 \\
\hline Written on appointment card only & 212 & 70.7 & 148 & 74.0 \\
\hline Verbally and written on card & 70 & 23.3 & 28 & 14.0 \\
\hline \multicolumn{5}{|c|}{ Have you ever missed your follow-up appointment? } \\
\hline Yes & 198 & 66.0 & 112 & 56.0 \\
\hline No & 102 & 34.0 & 88 & 44.0 \\
\hline \multicolumn{5}{|c|}{ Out of 10 scheduled follow-up appointments, on an average how many did you miss? } \\
\hline$>30 \%$ & 50 & 16.7 & 26 & 13.0 \\
\hline $1-30 \%$ & 148 & 49.3 & 86 & 43.0 \\
\hline None & 102 & 34.0 & 88 & 44.0 \\
\hline
\end{tabular}


Table 3: Respondents' reasons for missed medical appointments

\begin{tabular}{llll}
\hline S/N & Reasons for missed appointments & Hypertensive n (\%) & Diabetic n (\%) \\
\hline 1 & Forgot the appointment & $126(42.0)$ & $72(36.0)$ \\
2 & Financial constraints for logistics & $108(36.0)$ & $53(26.5)$ \\
3 & Conflicting commitments/Difficulty getting off work & $101(33.7)$ & $60(30.0)$ \\
4 & Felt well/No new complaints & $94(31.3)$ & $60(30.0)$ \\
5 & Discouraged by the long waiting time & $92(30.7)$ & $42(21.0)$ \\
6 & Too ill to attend & $74(24.7)$ & $84(42.0)$ \\
7 & Distance from the hospital & $75(25.0)$ & $33(16.5)$ \\
8 & Used alternative forms of treatment & $52(17.3)$ & $25(12.5)$ \\
9 & Poor relationship with healthcare provider & $45(15.0)$ & $40(20.0)$ \\
10 & Improper follow-up/Different physician seen at each visit & $41(13.7)$ & $11(5.5)$ \\
11 & Dissatisfaction with the quality of healthcare provided & $29(9.7)$ & $9.6(4.8)$ \\
12 & No perceived benefit of treatment & $26(8.6)$ & $7.6(3.8)$ \\
13 & No one to escort me to the hospital & $7(2.3)$ & $7(3.5)$ \\
14 & Perceived disrespect/negative attitude of healthcare provider & $14(4.7)$ & $19(9.5)$ \\
15 & Strike actions/Public holidays & $7(2.3)$ & $4(2.0)$ \\
\hline
\end{tabular}

Table 4: Level of respondents' awareness of the potential consequences of missed medical appointments on clinical outcomes and healthcare system

\begin{tabular}{|c|c|c|c|c|}
\hline \multirow[t]{2}{*}{ Variable } & \multicolumn{2}{|c|}{$\begin{array}{l}\text { Hypertension }(n=300) \\
\text { Frequency }(\%)\end{array}$} & \multicolumn{2}{|c|}{$\begin{array}{l}\text { Diabetes }(n=200) \\
\text { Frequency }(\%)\end{array}$} \\
\hline & Aware & Unaware & Aware & Unaware \\
\hline Reduces treatment benefits & $170(56.7)$ & 130 (43.3) & $104(52.0)$ & $96(48.0)$ \\
\hline Poor disease control & $56(18.7)$ & $244(81.3)$ & $90(45.0)$ & $110(55.0)$ \\
\hline Worsening of medical condition & $80(26.7)$ & $220(73.3)$ & $60(30.0)$ & $140(70.0)$ \\
\hline Development of complications & $72(24.0)$ & $228(76.0)$ & $54(27.0)$ & $146(73.0)$ \\
\hline $\begin{array}{l}\text { Increased waiting time due to unscheduled } \\
\text { visits }\end{array}$ & $125(41.7)$ & $175(58.3)$ & $75(37.5)$ & $125(62.5)$ \\
\hline $\begin{array}{l}\text { Increased patient inconveniences due to } \\
\text { unscheduled visits }\end{array}$ & $80(26.7)$ & $220(73.3)$ & $110(55.0)$ & $90(45.0)$ \\
\hline Reduced efficiency of healthcare provider & $50(16.7)$ & 250 (83.3) & $67(33.5)$ & $133(66.5)$ \\
\hline Disruption in healthcare & $86(28.7)$ & $214(71.3)$ & $67(33.5)$ & $133(66.5)$ \\
\hline Wastage of healthcare resources & $73(24.3)$ & $227(75.6)$ & $56(28.0)$ & $144(72.0)$ \\
\hline
\end{tabular}

Table 5: Relationships between appointment adherence and some variables

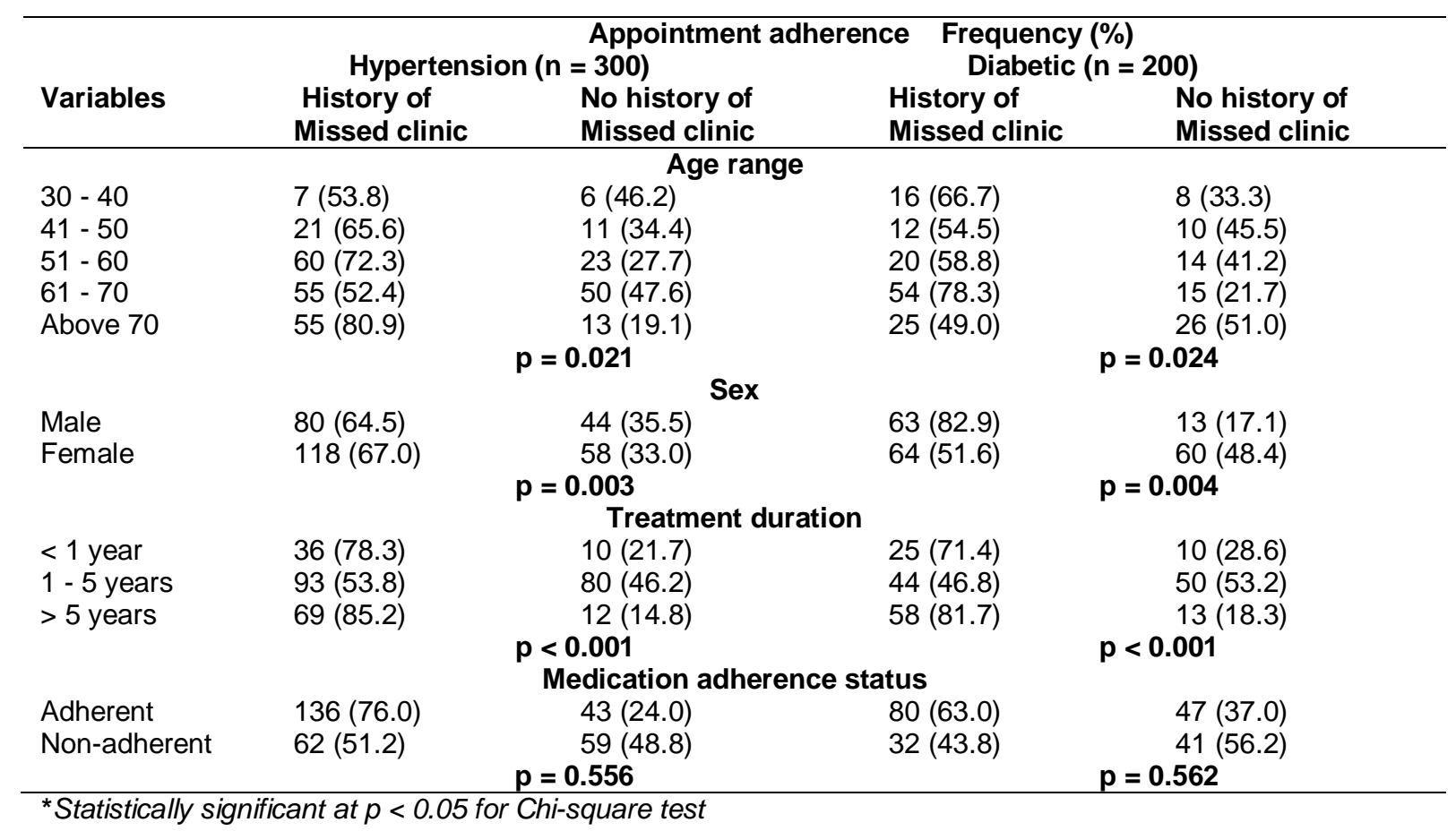




\section{DISCUSSION}

In this study $16.7 \%$ of the hypertensive respondents missed more than $30 \%$ of their scheduled follow-up appointments. A similar rate of $12.0 \%$ was reported in a cross-sectional survey of 185 hypertensive African-Americans in an urban medical center in Maryland, USA [3]. However, as high as $31.0 \%$ of hypertensive African-Americans followed in a community based practice in New York City missed more than $30.0 \%$ of follow-up appointments [15]. Among the diabetic respondents in this study, $13.0 \%$ missed more than $30 \%$ of their follow-up appointments. This is similar to the findings in a study among diabetic population in California, USA, where $12.0 \%$ missed more than $30 \%$ of scheduled appointments [4].

In this cross-sectional study, patients' gender and age range were associated with appointment adherence. While a study done among patients with selected chronic diseases in Uganda had found no association [16]; another study done among an underserved population at a Federallyfunded community health center in Massachusetts [17] reported association. A study also reported higher rates of nonattendance among women, one suggesting that childrearing and family responsibilities may play a part in non-attendance [18].

This study found no significant relationship between appointment adherence and medication adherence. There are conflicting views about the use of appointment adherence as a predictor of medication adherence. Findings from this study aligned with those of other investigators who suggest that appointment adherence is not an accurate substitute for medication taking behavior. For instance, in a cross-sectional study, Ogedegbe and his colleagues found no significant relationship between appointment adherence and medication adherence among 190 hypertensive African-Americans followed in a community health center in New York [15].].

Findings from this study support available literature on the diverse and multi-dimensional reasons cited by patients for appointments nonadherence. The top five reasons cited for missed medical appointments in this study include forgot the appointment, financial constraints, conflicting commitments/difficulty getting off work, felt well and discouraged by the long waiting time to assess healthcare. This corroborates findings by other investigators. Ngwenga et al, in a face-toface/telephone interview found forgetfulness to be the major cause of non-attendance among diabetic patients in South Africa [19]. In Ireland, a study in a gastroenterology outpatient clinic identified forgetting appointments and feeling well as reasons for no-show [20] while Mohammed and Al-Doghaither (2002) cited forgetfulness and lack of transport as the most common reasons for non-attendance [21].

Recent studies have investigated different interventions to curb the high no-show rates in clinics. Strategies that have been tried include reducing waiting time, improving patient communication with healthcare providers, using open access scheduling systems, patient education and assessing of financial penalties for missed appointments [10]. In order to reduce noshow, most hospitals and clinics either modify their appointment scheduling strategies or incorporate some forms of appointment reminder strategies [22]. Majority of respondents in this study are strongly of the opinion that reminder systems would be an effective strategy to reduce no-show rates.

The level of awareness of the respondents on the possible impact of missed medical appointment is low. This is similar to the low level of awareness of the impact of missed appointment reported in a study in maternal healthcare clinics in Saudi Arabia [23]. Improved and continuous patient education on the importance of follow-up visits will significantly influence adherence to aspect of disease management as well as improve selfmanagement practices and treatment outcomes [24].

About two-thirds of the hypertensive as well as the diabetic respondents were of the opinion that patients who miss medical appointments should be punished. Majority of the respondents also proposed that patients who miss their medical appointments should only be attended to after those on schedule for that day have been attended to as a means of punishing them. However, most of the respondents were not favorably disposed to the opinion of fining those who miss medical appointments. This is contrary to reports from Denmark, a qualitative survey showed that patients generally have a positive attitude towards implementation of nonattendance fees [25].

\section{Limitations of the study}

Although in literature multi-measure approach is often recommended in measuring medication adherence, this study used a self-report scale which has its inherent drawbacks. Patients' ability to understand the questions and willingness to disclose information may affect 
response accuracy. However, the medication adherence scale is a validated tool that has been judged suitable for the study population.

Patients self-report on the frequency of missed medical appointment is dependent on patients' recall ability and also subject to bias.

\section{CONCLUSION}

The reasons for missed medical appointment was explored, as well as awareness of patients on its consequences. Forgetfulness, transportation/ financial constraints, , conflicting commitments/ difficulty getting off work, feeling well and discouraged by the long waiting time were the most common reasons cited for missed medical appointments. There was no significant association between appointment adherence and medication adherence. Majority of the respondents would have un-booked patients delayed until all the scheduled patients are seen as a means of reducing appointment nonadherence.

It is recommended that both verbal and written appointment format be adopted for patients. Also, patients who do not adhere to their appointment scheduled should be attended to only after attending to those on schedule so as to discourage appointment.

\section{DECLARATIONS}

\section{Acknowledgement}

None.

\section{Conflict of Interest}

No conflict of interest associated with this work.

\section{Contribution of Authors}

The authors declare that this work was done by the authors named in this article and all liabilities pertaining to claims relating to the content of this article will be borne by them.

\section{Open Access}

This is an Open Access article that uses a funding model which does not charge readers or their institutions for access and distributed under the terms of the Creative Commons Attribution License (http://creativecommons.org/licenses/by/ 4.0) and the Budapest Open Access Initiative (http://www.budapestopenaccessinitiative.org/rea d), which permit unrestricted use, distribution, and reproduction in any medium, provided the original work is properly credited.

\section{DECLARATIONS}

\section{Acknowledgement}

None.

\section{Conflict of Interest}

No conflict of interest associated with this work.

\section{Contribution of Authors}

The authors declare that this work was done by the authors named in this article and all liabilities pertaining to claims relating to the content of this article will be borne by them.

\section{Open Access}

This is an Open Access article that uses a funding model which does not charge readers or their institutions for access and distributed under the terms of the Creative Commons Attribution License (http://creativecommons.org/licenses/by/ 4.0) and the Budapest Open Access Initiative (http://www.budapestopenaccessinitiative.org/rea d), which permit unrestricted use, distribution, and reproduction in any medium, provided the original work is properly credited.

\section{REFERENCES}

1. Chobanian AV, Bakris GL, Black HR, Cushman WC, Green $L A$, Izzo JL Jr, Jones DW, Materson BJ, Oparil S, Wright JT Jr, et al. "The seventh report of the joint national report on prevention, detection, evaluation, and treatment of high blood pressure: the JNC 7 report". JAMA 2003; 289(19): 2560-2572.

2. World Health Organisation. Chronic diseases and health promotion: Preventing chronic diseases: a vital investment. Geneva. WHO 2012. Available from http://www.who/int/chp/chronic_diseases report/part 1/en/index 14. Accessed [Dec 1, 2016].

3. Nwabuo CC, Dy SM, Weeks K, Young JH. Factors associated with appointment Non-Adherence among African-Americans with Severe, poorly controlled Hypertension. PLOS ONE 2014; 9(8): e103090.

4. Karter AJ, Parker MM, Moffet HH, Ahmed AT, Ferrara A, Liu JY, Selby JV. Missed appointments and poor glycemic control: an opportunity to identify high-risk diabetic patients. Med Care 2004; 42(2): 110-115.

5. Cienchanowski P, Russo J, Katon W, Simon G, Lundman E, Von Korff M, Young B, Lin E. Where is the patient? The association of psychosocial factors and missed 
primary care appointments in patients with diabetes. Gen Hosp Psychiatry 2006; 28(1): 9-17.

6. Nuti LA, Lawley M, Turkcan A, Tian Z, Zhang L, Chang K, Willis $D R$, Sands $L P$. No-shows to primary care appointments: subsequent acute care utilization among diabetic patients. BMC Health Serv Res 2012; 12: 304. DOI: 10.1186/s12913-015-0938-5

7. Mbada CE, Nonvignon J, Ajayi O, Dada OO, Awotidebe TO, Johnson OE, Olarinde A. Impact of missed appointments for out-patient physiotherapy on cost, efficiency and patients' recovery. Hong Kong Physiother J 201331(1): 30-35.

8. Macharia WM, Leon G, Rowe BH, Stephenson BJ, Haynes RB. An Overview of interventions to improve compliance with appointment keeping for medical services. JAMA 1992; 267(13): 1813-1817.

9. Martini da Costa T, Salomâo PL, Martha A, Pisa IT, Sigulem $D$. The impact of short message service text messages sent as appointment reminders to patients cell phones at outpatient clinics in Sâo Paulo, Brazil. Int $J$ Med Inform 2009; 79: 65-70.

10. Salameh E, Olsen S, Howard D. Non-attendance with clinic follow-up appointments: Diabetes as exemplar J Nurse pract. 2012; 8(10): 797-803.

11. Sharp DJ, Hamilton W. Non-attendance at general practice and outpatients clinic. BMJ 2001; 323: 1081 1082.

12. Snežana, Bošnjak. "The declaration of Helsinki: The cornerstone of research ethics". Archive of Oncology 2001; 9 (3): 179-184.

13. Yamane T. Statistics: An Introductory Analysis, 2nd Ed, New York, Harper and Raw 1967.

14. Morisky DE, Green LW, Levine DM. Concurrent and predictive validity of a self-reported measure of medication adherence. Med Care 1986; 24: 67-74.

15. Ogedegbe G, Schoenthaler A, Fernandez $S$. Appointment-keeping behaviour is not related to Medication Adherence in Hypertensive African Americans. J Gen Intern Med 2007; 2298: 1176- 1179.

16. Paterson V, Charlton $P$ and Richard S. Nonattendance in chronic disease clinics: a matter of noncompliance.
Journal of Nursing and Healthcare in chronic illness 2010; 12(1): 63-74.

17. Kalyango JN, Hall M, Karamagi C. Appointment keeping for medical review among patients with selected chronic diseases in an urban area of Uganda. Pan Afr Med $J$ 2014; 19: 229. DOI: 10.11604/pamj.2014.19.229.3971

18. Kinney R, Savageau J, Lemay C, Cashman S, Middleton $E L$, Hason A. Factors related to the failure to keep appointments in an underserved population at a federally funded community. 2001; 18: 196-197.

19. McEvoy B, Nydegger R, Williams G. Factors related to patient compliance in the treatment of acne vulgaris. Int J Dermatol 2003; 42(4): 274-280.

20. Ngwenga BT, Van ZylDG, Webb EM. Factors influencing non-attendance of clinic appointments in diabetic patients at a Gauteng Hospital in 2007/2008. JEMDSA 2009; 14(2): 106-109.

21. Murdock A, Rodgers C, Lindsay H, Tham TC. Why do patients not keep their appointments? Prospective study in a gastroenterology outpatient clinic. $J R$ Soc Med 2002 Jun; 95(6): 284-286.

22. Kasem AA, Althobaiti TS, Al-Jeaid DAS, Al-Osaimi SM. An analysis of causes behind missed scheduled appointments at outpatient ENT clinics. The Egypt $J$ Otolaryngol 2015; 31(1): 1-3.

23. Perron NJ, Dao MD, Kossovsky MP, Miserez, Chuard C, Calmy A, Gaspoz JM. Reduction of missed appointments at an urban primary care clinic: a randomised controlled study. BMC Fam Pract 2010; 25(11): 79. DOI: 10.1186/1471-2296-11-79

24. Almalki A. Missed appointment at maternal healthcare clinics in Riyadh city: reasons and associated factors. $J$ Health admin. 2014; 3(4): 8. DOI: 10.5455/ijmsph.2013.2.256-265

25. Thompson AC, Thompson MO, Young DL, Sanislo SR, Moshtdghi DM, Singh K. Barriers to follow-up and strategies to improve adherence to appointment for care of chronic eye diseases. Invest Ophthalmol Vis Sci 2015; 56(8): 4324-4331. 